\title{
On the effects of Turbocharger on Particle Number and Size Distribution in a Heavy - Duty Diesel Engine
}

\author{
Prasath K., Arun ; Bernemyr , Hanna ; Erlandsson, Anders
}

Published in:

S A E Technical Papers

Link to article, DOI:

10.4271/2020-24-0007

Publication date:

2020

Document Version

Publisher's PDF, also known as Version of record

Link back to DTU Orbit

Citation (APA):

Prasath K., A., Bernemyr, H., \& Erlandsson, A. (2020). On the effects of Turbocharger on Particle Number and Size Distribution in a Heavy - Duty Diesel Engine. S A E Technical Papers, 2020, [2020-24-0007]. https://doi.org/10.4271/2020-24-0007

\section{General rights}

Copyright and moral rights for the publications made accessible in the public portal are retained by the authors and/or other copyright owners and it is a condition of accessing publications that users recognise and abide by the legal requirements associated with these rights.

- Users may download and print one copy of any publication from the public portal for the purpose of private study or research.

- You may not further distribute the material or use it for any profit-making activity or commercial gain

- You may freely distribute the URL identifying the publication in the public portal 


\title{
On the Effects of Turbocharger on Particle Number and Size Distribution in a Heavy - Duty Diesel Engine
}

\author{
Arun Prasath K and Hanna Bernemyr KTH Royal Institute of Technology
}

Anders Erlandsson KTH Royal Institute of Technology/DTU

Citation: Arun Prasath, K., Bernemyr, H., and Erlandsson, A., "On the Effects of Turbocharger on Particle Number and Size Distribution in a Heavy - Duty Diesel Engine," SAE Int. J. Advances \& Curr. Prac. in Mobility 3(2):882-893, 2021, doi:10.4271/2020-24-0007.

This article was presented at the Conference on Sustainable Mobility, Catania, Italy, Oct. 4-7, 2020.

\section{Abstract}

3 articles emitted from internal combustion engines have adverse health effects and the severity varies based on the particle size. A diesel particulate filter (DPF) in the after-treatment systems is employed to control the particle emissions from combustion engines. The design of a DPF depends on the nature of particle size distribution at the upstream and is important to evaluate. In heavy-duty diesel engines, the turbocharger turbine is an important component affecting the flow and particles. The turbine wheel and housing influence particle number and size. This could potentially be used to reduce particle number or change the distribution to become more favourable for filtration. This work evaluates the effect of a heavy-duty diesel engine's turbine on particle number and size distribution. The particle number (PN) emissions is measured with regard to varying turbine inlet conditions namely: turbine inlet temperature, exhaust mass flow rate and particle concentration at the turbine inlet (by varying fuel injection pressures). It was found that at turbine inlet temperatures of $200^{\circ} \mathrm{C}, \mathrm{PN}$ remains almost constant as the particles were assumed to be held together by the volatile material. However, at $300^{\circ} \mathrm{C}$ there was an increase in $\mathrm{PN}$ across the turbine, and the increase was higher at higher mass flow rates across the turbine. Furthermore, lower injection pressures exhibited a higher rise in PN across the turbine. Interestingly, at $400^{\circ} \mathrm{C}$, a reduction in $\mathrm{PN}$ across the turbine was observed due to oxidation. This reduction in $\mathrm{PN}$ was lesser while there was an increase in mass flow rate. Additionally, with higher injection pressures, a higher reduction in $\mathrm{PN}$ was noticed. This result is promising as catalyst coated turbine wheels could potentially enhance the effect thereby reducing $\mathrm{PN}$ before the after-treatment system.

\section{Introduction}

$\int$ articles emitted from internal combustion engines (ICE) in heavy-duty (HD) applications are a matter of concern for emissions as they affect health [1]. The particle size distribution provides an indication of the parts in the respiratory system where the particles are most likely to deposit [2]. Owing to the health concerns, Euro VI emission stage, for HD applications, regulates the total particle number (PN) emitted, like in the light-duty (LD) applications []ㅡ.

The particles emitted by diesel engines are chain-like aggregates, consisting of primary particles with each particle aggregate containing many agglomerates and further connected to each other [4]. The size of the particle is higher if the agglomerates connected are more in number. Based on the sizes, particles can be classified into three groups viz.: nuclei mode (3-30 nm), accumulation mode (30-500 nm) and coarse mode $(>1 \mu \mathrm{m})$ particles []․

A diesel particulate filter (DPF) in the exhaust after-treatment system is employed to control the particles in the tailpipe.
The design of a DPF depends on the nature of particle size distribution at the upstream and is important to evaluate [므, 7]. For this evaluation, one can trace from the start of the particle core formation. Particle core formation happens during the combustion process in the engine giving rise to the particles in the nucleation mode and the tail-pipe emission of the particles depends on the type of exhaust treatment system [ $\underline{8}$ ].

In heavy-duty (HD) diesel engines, the turbocharger turbine is an important component affecting the flow and particles. Not many studies have focused on the effect of the turbine in the turbocharger, on the particle emissions in the exhaust. The studies discussing the effect of turbine on particles are discussed below.

Cucchi and Samuel [9] have reported a study on the effect of turbochargers on the particle emissions with a gasoline direct injection engine (GDI). An experimental matrix was made to sweep the speed and load of the engine, wherein three engine speeds and four load points have been taken for the analysis of PN across the turbocharger. The fuel injection

(c) 2020 The Authors. Published by SAE International. This Open Access article is published under the terms of the Creative Commons Attribution License (http://creativecommons.org/licenses/by/4.0/), which permits distribution, and reproduction in any medium, provided that the original author(s) and the source are credited. 
pressure was not controlled, and it increased with the engine load. The results show that the total PN decrease at low loads whilst high loads there was an increase in total PN across the turbocharger. It was concluded that the turbine was promoting agglomeration and growth. Across the turbocharger, large size particles were getting fragmented into smaller size particles. The same research group [10] also developed a 1-D model to estimate the post-turbocharger total particle number using the pre-turbocharger total particle number and the turbine flow parameter using the Lambert $\mathrm{W}$ function (Omega function). In the experimental study [9], the coefficient of variation of the PN measurements was very high to about $25 \%$. Here the test matrix was with respect to varying engine operating conditions and not with respect to the turbocharger. A similar experiment with the turbine as the test subject, and with the experimental design for the turbine inlet conditions could be of interest to analyze the impact of the turbocharger on the particle number emissions for exploring the possibilities of potential PN reduction across the turbocharger.

Lee and Zhu [11] have observed that the size of the particles before the turbocharger was larger than the particles after the turbocharger in a LD diesel engine at $2500 \mathrm{rpm}$ and $25 \%$ load. In the same study, it was also observed that the morphology of particles before the turbocharger was loosely packed agglomerates. Whereas, the particles after diesel oxidation catalyst (DOC) were dense and fused together due to oxidation and were more spherical in nature. Therefore, there is a higher possibility to alter the nature of particles before the turbocharger than to alter the same after the diesel oxidation catalyst.

A DPF placed before the turbocharger (pre DPF) can have higher rate of passive regeneration due to higher exhaust temperature than the DPF placed after the turbocharger (conventional DPF) this in turn leads to lesser pressure drop across the DPF [12]. In addition, the average soot loading of the DPF between active regeneration decreases. In the same study, it was also noted that the pulse energy to the turbocharger decreases with the pre DPF leading to higher pumping work. As there is the issue of higher pumping work in using a pre DPF, using the turbocharger as a part of the exhausttreatment system along with a conventional DPF could be an alternative possibility for effective $\mathrm{PN}$ reduction. Besides the higher exhaust temperature before the turbocharger, turbulence is also higher than downstream of the turbocharger [13]. These properties of the exhaust can be explored with respect to the turbocharger in reducing PN effectively along with the conventional exhaust after-treatment system. Understanding the behavior of particles across the turbine of the turbocharger with respect to heavy-duty diesel engine can be useful for HD applications for revaluating the exhaust after-treatment system. This work aims to study the effect of the turbine on particle number emissions with various turbine inlet conditions.

The conditions at the turbine inlet may influence the outlet particle number emissions. The hypotheses behind this study are listed as follows: (i) Higher exhaust mass flow rates may favour the impingement of larger size particles against the turbine surfaces as they are less likely to follow the flow streamlines due the higher inertia in turn causing fragmentation into smaller size particles. (ii) The temperature at the turbine inlet may have little or no effect on the number and size distribution of the particles at the outlet due to the limited impact on the particle dynamics. (iii) A higher particle concentration may have a strong influence on the particle number variation across the turbine due to increased particle interaction leading to higher collision and fragmentation.

\section{Objectives}

The objective of this work is to evaluate the effect of various turbine inlet conditions on the particle number $(\mathrm{PN})$ in a constant geometry turbocharger of a Euro VI HD diesel engine in steady state operation. The parameters swept in the experiment were (i) the temperature at the turbine inlet, (ii) the exhaust mass flow rate and (iii) the particle concentration at the turbine inlet.

\section{Experimental Setup}

The experiments were performed in a 6-cylinder Euro VI HD Diesel engine with a constant geometry turbocharger. The specifications of the engine are shown in Table 1 . The exhaust treatment systems of the engine were Diesel Oxidation Catalyst (DOC), Diesel Particulate Filter (DPF) and Selective Catalytic Reduction (SCR) unit. An electrical dynamometer was used to load the engine. The engine was run on commercially available Swedish low sulphur S10 diesel.

\section{Turbocharger and Measurement Provisions}

The turbocharger in the engine was a constant geometry turbocharger with a twin entry at the inlet. The turbine was a radial type turbine and the compressor was a centrifugal type compressor. The control for the waste gate operation was disengaged. A spacer (between the exhaust manifold and the turbocharger) was fabricated to enable the provisions for preturbo measurements. The thickness of the spacer was $20 \mathrm{~mm}$. Post-turbo measurements were taken at least $20 \mathrm{~cm}$ after the turbo outlet after the exhaust brake throttle. This is to minimize the highly rotational flow at the outlet of the turbine. The measurements taken at pre and post turbine locations are namely particle number measurements, temperature and time-resolved pressure. A single particle measuring probe (multi-hole type) was fitted across both inlets. Pressure and temperature were separately measured at both the inlets of the turbine. The thermocouples for temperature measurement were positioned for the centre of the flow at both the inlets.

TABLE 1 Specifications of the engine [23]

\begin{tabular}{l|l}
\hline Engine & Scania D13 \\
\hline Bore & $130 \mathrm{~mm}$ \\
\hline Stroke & $160 \mathrm{~mm}$ \\
\hline Connecting Rod & $255 \mathrm{~mm}$ \\
\hline Compression ratio & $18: 1$ \\
\hline Number of Cylinders & 6 (In-line) \\
\hline Turbocharger & $\begin{array}{l}\text { Twin-entry fixed geometry } \\
\text { turbocharger }\end{array}$ \\
\hline Power & $490 \mathrm{hp}(365 \mathrm{~kW})$ \\
\hline
\end{tabular}

Reprinted with permission from Ref. [23], Table 1. (c) SAE International. 


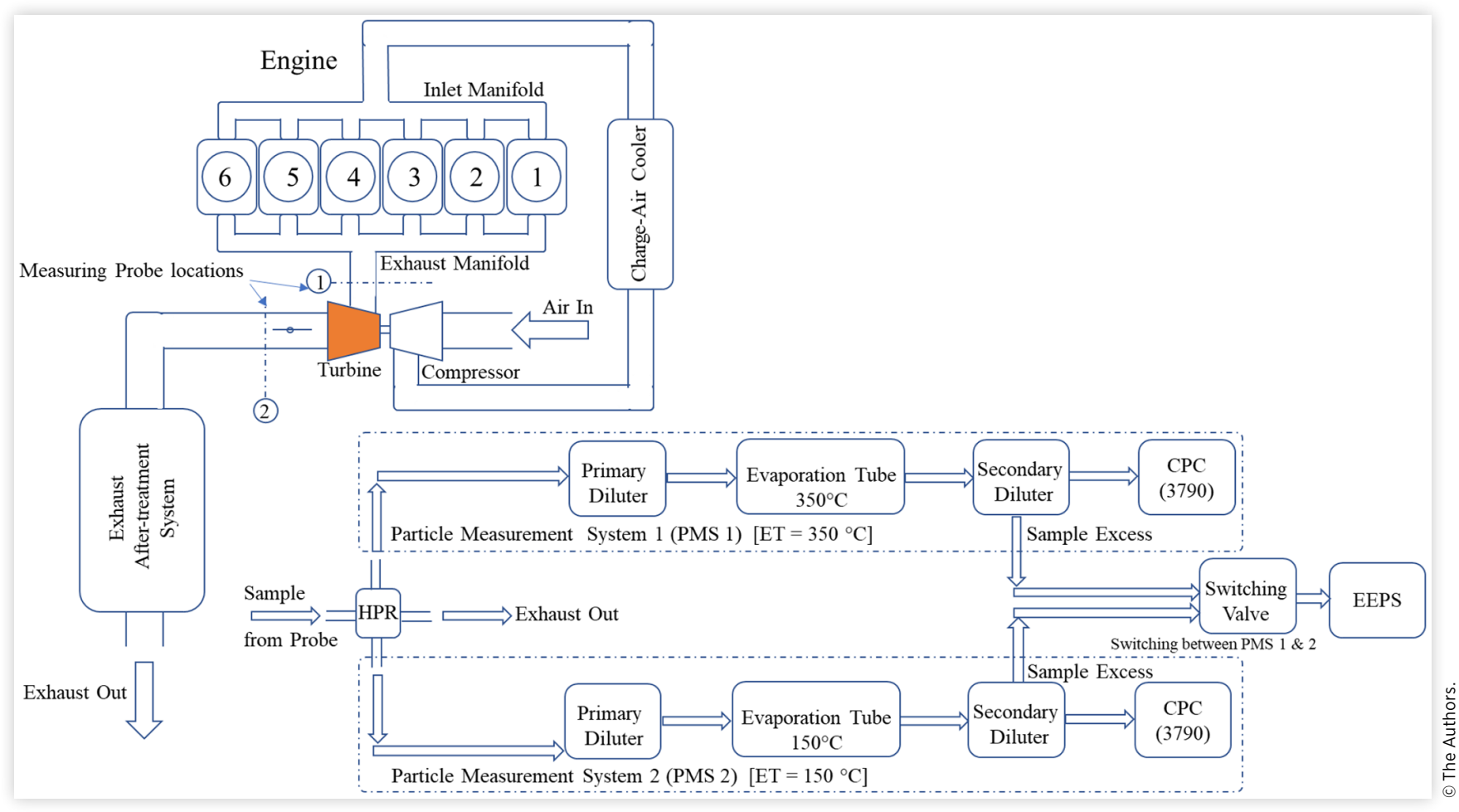

\section{Particle Measurement System}

Two particle measurement systems (PMS 1\&2) were used to measure the total PN emissions. PMS1 is a PMP compliant PN measurement instrument. The instrument has a twostage dilution system with an evaporation tube maintained at $350^{\circ} \mathrm{C}$ to measure non-volatile particles. PMS 2 is similar to PMS1 but with the evaporation tube temperature was maintained at $150^{\circ} \mathrm{C}$ to measure volatile and non-volatile particles. Both PMS $1 \& 2$ are capable of measuring particles from $23 \mathrm{~nm}$ and are of the same make, APC (AVL Particle Counter: APC 489).

The particle size distribution was measured using the EEPS (Engine Exhaust Particle Sizer Spectrometer: TSI 3090). The size distribution measured by the EEPS is in the range of $5.6 \mathrm{~nm}$ to $560 \mathrm{~nm}$. The excess output from the secondary dilution of PMSs was used as the conditioned sample inlet for EEPS. The particle number measurements reported with both PMS 1\& 2 were corrected for dilution factors and stated losses by the manufacturer based on the calibration. Whereas, the measurements from EEPS were corrected only for the dilution conditions manually. The schematic of the particle measurement systems are shown in the overall experimental setup in Figure 1.

For each engine operating point, measurements were taken for three measurement trials (sampling periods) to ensure repeatability. While using the PMS 1\& 2, each sampling trial was at least 120 seconds, at $5 \mathrm{~Hz}$ measurement and data logging frequency. In the case of the particle size distribution measurement, each trial was 120 seconds at $10 \mathrm{~Hz}$ measurement and data logging frequency using the EEPS.

\section{Sampling}

Particle measurements were taken pre and post turbine using a multi-hole probe as described earlier. The pre and post turbine sampling lines were connected to a switching valve. The switching valve was made using two temperature resistant ball valves so that the sample flow is not disturbed. The outlets of the valves were combined into a single line to connect to the sample inlet of the instrument. Here, a high-pressure reducer (HPR) provided by the APC manufacturer was used before the sample inlet to the instrument in order to reduce the high exhaust backpressures, as the sampling was done as a raw gas exhaust measurement upstream to the DPF. The loss of particles in the HPR is independent of the exhaust backpressures at the inlet of the HPR [14]. The total length of the sampling line (stainless steel) used from the point of measurement to the primary diluter was $2.3 \mathrm{~m}$. The residence time from the point of measurement to the primary dilution was $0.78 \mathrm{~s}$ which is within the limits $(\leq 3 \mathrm{~s})$ of PMP. The sampling conditions and length of the transfer line were kept the same at inlet (1) and outlet (2), and the points of measurement are shown in Figure 1.

\section{Methodology}

The experiments were performed on a Euro VI HD engine. The control for the waste-gate of the turbocharger was disengaged throughout the experiments. Also, the exhaust brake was not used. The experiments were designed to sweep the turbine inlet conditions. The exhaust conditions considered here were temperature at the inlet of the turbine, exhaust mass 


\section{FIGURE 2 Design of Experiments}

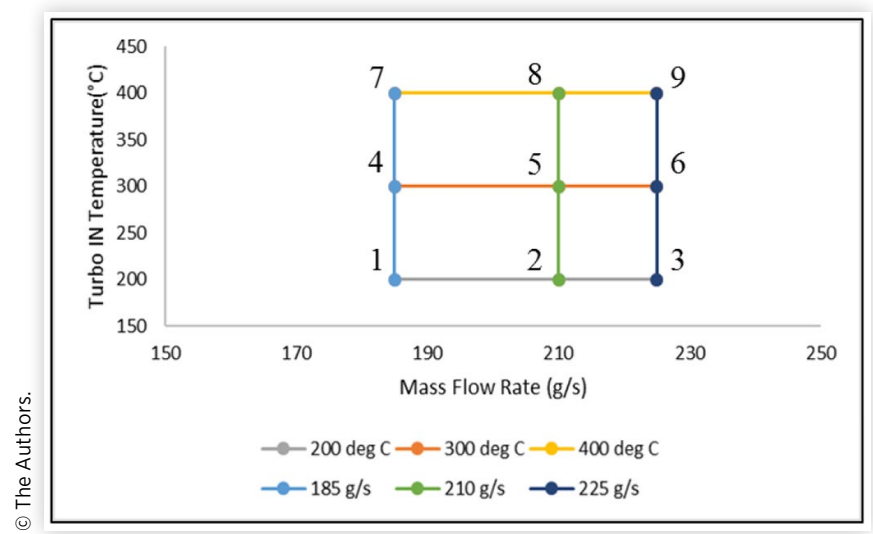

FIGURE 3 Actual operating points in the engine speed torque plot

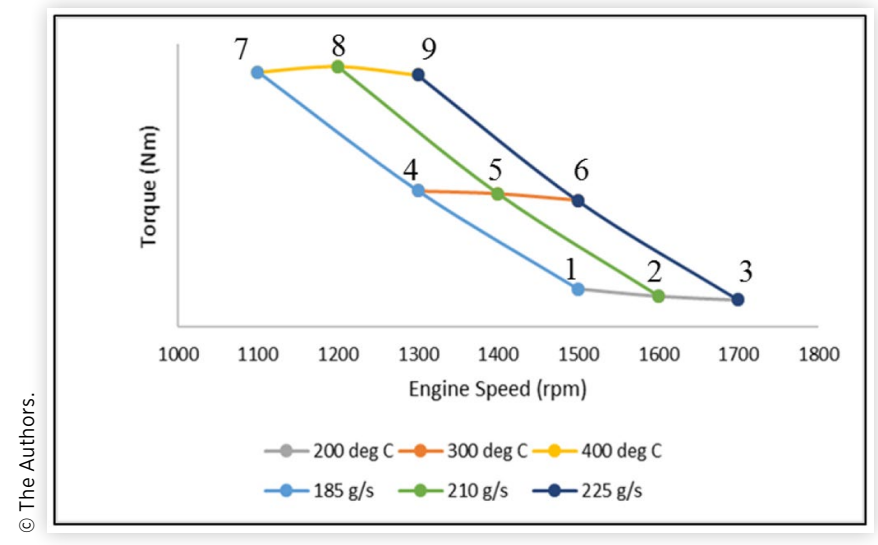

flow rate, and particle concentration at the inlet of the turbine. The temperatures evaluated at the inlet of the turbine (Turbo IN temperature) were $200^{\circ} \mathrm{C}, 300^{\circ} \mathrm{C}$ and $400^{\circ} \mathrm{C}$. The evaluated exhaust mass flow rates through the turbine were $185 \mathrm{~g} / \mathrm{s}, 210$ $\mathrm{g} / \mathrm{s}$ and $225 \mathrm{~g} / \mathrm{s}$. These have been denoted in Figure 2. Hence in this design, turbine is the system of interest and the design was with respect to the turbine and not the engine conditions.

The particle concentration was varied by altering the injection pressures. As the injection pressure increases, the engine out total PN concentration reduces and more particles gets emitted in nucleation mode [15]. To facilitate in the experiments, for the same operating points described above, different injection pressures namely 800 bar, 1000 bar and 1200 bar was used while maintaining the start of injection constant at top dead centre (TDC). Hence a total of 27-operating points were performed in this experimental campaign.

The error in the temperature measurements was $\pm 5^{\circ} \mathrm{C}$ from the mean value. The error in mass flow measurements was $\pm 5 \mathrm{~g} / \mathrm{s}$ from the mean value. The error in the injection pressure measurements was \pm 20 bar from the mean value.

The experiments were conducted at a constant exhaust temperature by varying speeds in steps of $100 \mathrm{rpm}$. The speed was first fixed and then the torque was increased so that the Turbo IN temperatures were maintained constant to a desired temperature. The experiment was done from lower speed to higher speed as the flow rate increases with higher speed. This in turn increases the heat capacity of the exhaust flow. The lowest exhaust temperature $\left(200^{\circ} \mathrm{C}\right)$ was fixed such that the lowest torque is sustainable with minimum injected fuel quantity. Having completed the first set of constant temperature operating points, other exhaust temperature operating points were performed in steps of $100^{\circ} \mathrm{C}$. The process was repeated at $200^{\circ} \mathrm{C}$ operating points. The flow rate of the exhaust was calculated as the sum of mass flow rate of air and diesel $\left(\dot{\mathrm{m}}_{\mathrm{air}}+\dot{\mathrm{m}}_{\text {diesel }}\right)$. Along a constant temperature line, operating points analyzed from left to right in Figure 2 and Figure 3 describes the effect of mass flow rate. Similarly, along a constant mass flow rate line, operating points are analyzed from bottom to top in Figure 2 and Figure 3 describes the effect of turbo IN temperature. All measurements at each operating point were performed at steady state with constant exhaust temperature before the turbocharger.

The actual operating points in the engine speed torque plot is shown in Figure 3 .

\section{Data Analysis}

In these experiments, $\mathrm{PN}$ measurements were made between inlet (1) and outlet (2) of the turbine as shown in Figure 1. The change in total PN between inlet and outlet with respect to inlet (in \%) was calculated as shown in Equation (1).

$$
\text { Change in } P N(\%)=\frac{\text { Oulet } P N-\text { Inlet } P N}{\text { Inlet } P N} \cdot 100
$$

Change in $\mathrm{PN}(\%)$ is positive when there is an increase in the total number of particles across the turbine; on the other hand if the value is negative then there is a decrease in the total number of particles across the turbine. Each measurement was taken for three sampling trials. Each trial was taken for at least 120 seconds at $5 \mathrm{~Hz}$ frequency as described earlier. Thus, each engine operating point had at least 1800 measurement points. All three trials were merged and averaged for the actual PN for each operating point. The standard deviation with respect to the mean $\mathrm{PN}$ was calculated as $\mathrm{CoV}$ (coefficient of variation) as shown in the Equation (2). The $\mathrm{CoV}$ (maximum of inlet and outlet; maximum along a trendline) in percentage is shown as the error bars in the figures. Also, the $95 \%$ confidence interval of the data points were well within the $\mathrm{CoV}$ limits.

$$
\operatorname{CoV} \text { of } P N(\%)=\frac{\text { Standard deviation of } P N}{\text { Mean } P N} \cdot 100
$$

The inversion matrix used in calculating the particle number distribution by EEPS was made for soot-like agglomerate particles. The results of the inversion matrix matches with the Scanning Mobility Particle Sizer (SMPS) results even when plotted with the volume distribution for larger particles. Hence the soot particles were regarded as spherical particles in the calculations [16].

The particle surface distribution was calculated from the particle number distribution measurements, assuming spherical particles (Equation (3)) [17].

$$
S=n \pi D_{p}^{2}
$$

The particle volume distribution was calculated from the particle number distribution measurements, assuming spherical particles (Equation (4)) [17].

$$
V=n \frac{\pi}{6} D_{p}^{3}
$$




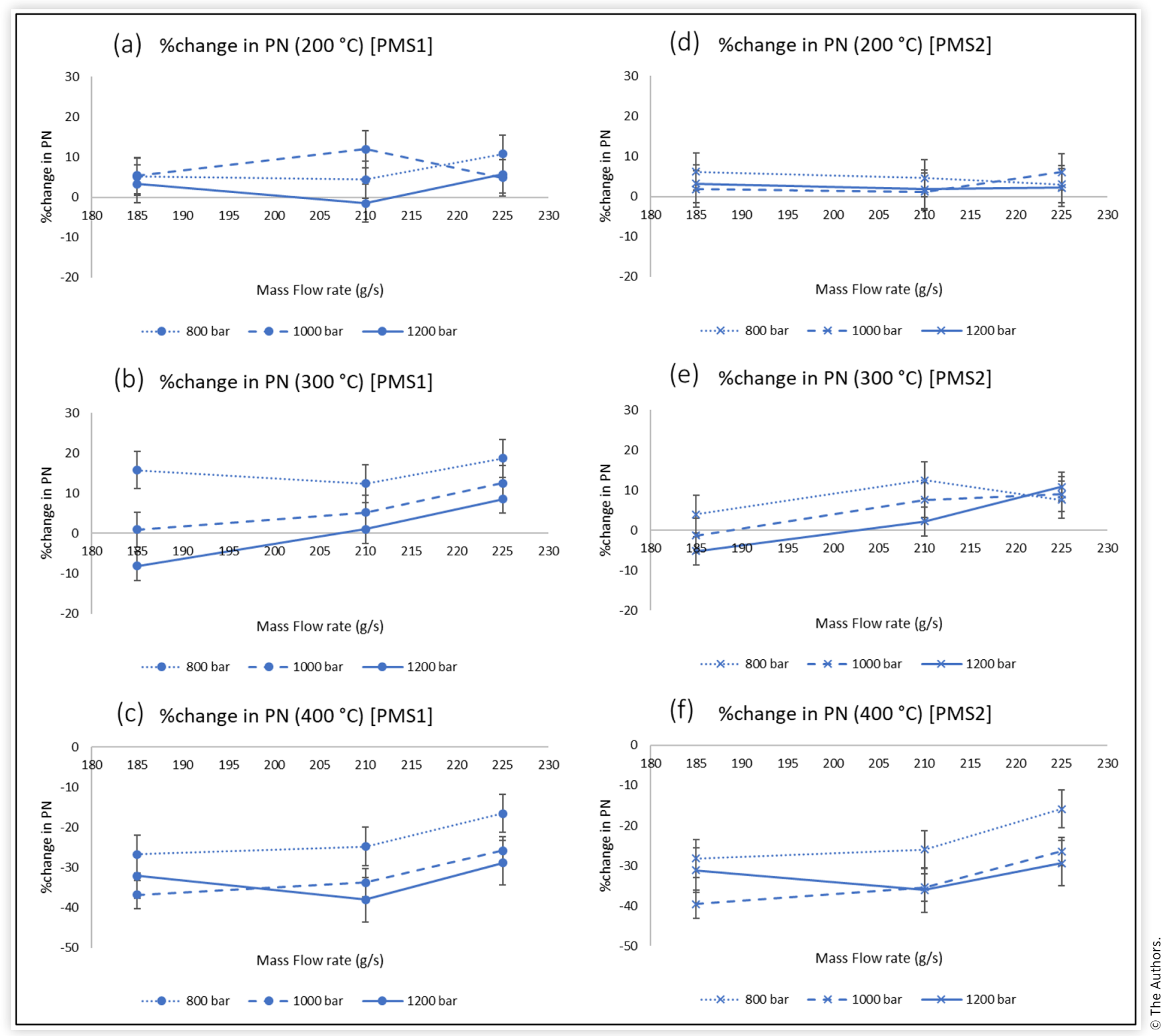

\section{Results}

The results from the experiments are described in this section under two sub-headings namely.

i. Effect of Turbine on total particle number

ii. Effect of Turbine on particle number distribution

\section{Effect of Turbine on Total Particle Number}

The change in total PN across the turbine is calculated using Equation (1). The results are presented as relative change with respect to the inlet $\mathrm{PN}$ (in \%).

Figure 4 shows the changes in total PN with respect to the inlet PN using PMS1 and PMS2. The left hand side (sub-figures a, b and c) of Figure 4 presents the results using the particle measuring system (PMS1) including a heater at $350^{\circ} \mathrm{C}$ implying that the volatile material has been evaporated prior to detection of the particles. Whereas the right hand side (sub-figures $d$, e and f) of Figure 4 presents the results using the particle measuring system (PMS2) including a heater at $150^{\circ} \mathrm{C}$ implying that the volatile material is included in the detection of particles. Within each sub-figure, the data is presented for the changes in $\mathrm{PN}$ with respect to the inlet PN at different mass flow rates of $185 \mathrm{~g} / \mathrm{s}, 210 \mathrm{~g} / \mathrm{s}$ and $225 \mathrm{~g} / \mathrm{s}$ along with different fuel injection pressures.

As described in the methodology section, the exhaust temperature increases with a decreasing engine speed while keeping a fixed exhaust mass flow rate. Analyzing sub-figures from top to bottom in Figure 4 describe the effect of increasing Turbo IN temperature. Comparing sub-figures to the left and right shows the effect of non-volatile PN and volatile included PN. 
In Figure 4, a comparison between sub-figures $\mathrm{c}$ and $\mathrm{f}$ to other sub-figures, shows that the change in $\mathrm{PN}$ with respect to the inlet $\mathrm{PN}$ was positive in value for all points with Turbo IN temperature as $200^{\circ} \mathrm{C}$ and $300^{\circ} \mathrm{C}$, meaning an increase in $\mathrm{PN}$ across the turbine except the point at $185 \mathrm{~g} / \mathrm{s}$ and $300^{\circ} \mathrm{C}$ in the 1200 bar case where the change in PN became negative. On the other hand, at all operating points with Turbo IN temperature as $400^{\circ} \mathrm{C}$, it can be noticed that values are negative, denoting a reduction in particles across the turbine.

In Figure 4a, the change in $\mathrm{PN}$ with respect to the inlet $\mathrm{PN}$ at $200^{\circ} \mathrm{C}$ was positive for all points using PMS1, meaning an increase in PN across the turbine. However, the relative change in PN has no clear trend with respect to the exhaust mass flow rate. Whilst with Figure $4 \mathrm{~d}$, it can be seen that there is no change in PN for all three injection pressures and for all three mass flow rates using PMS2. This shows that the particles at $200^{\circ} \mathrm{C}$ were well sticking to each other by volatile material among particles.

From Figure $4 \mathrm{~b}$, at $300^{\circ} \mathrm{C}$ of Turbo IN temperature, the total PN at the outlet was observed to increase with respect to the inlet PN for most flow rates and injection pressures. Only at $185 \mathrm{~g} / \mathrm{s}$ flow rate and 1200 bar injection pressure does the change become negative. Overall, it was also seen that the percentile change in $\mathrm{PN}$ increased with higher flow rate. At $300^{\circ} \mathrm{C}$, lower injection pressures exhibited higher magnitude of change in PN in most cases. A similar trend was observed with PMS2 (see Figure 4e) but for the highest flow rate as the particles may not fully devoid of volatiles owing to lesser residence time of particles at the turbine.

From Figure 4c, the change in $\mathrm{PN}$ with respect to the inlet at $400^{\circ} \mathrm{C}$ was always negative, denoting a clear decrease in the number of particles across the turbine. With the increase in mass flow rate, the reduction of $\mathrm{PN}$ across the turbine decreases as can be observed with the magnitude of reduction. It is also to be noted that the exception was the 1200 bar line at $185 \mathrm{~g} / \mathrm{s}$. At this point, the reduction of $\mathrm{PN}$ across the turbine was less when compared to the point at $210 \mathrm{~g} / \mathrm{s}$. The highest reduction was always exhibited at higher injection pressures except for the 1200 bar injection point at $185 \mathrm{~g} / \mathrm{s}$. This is explained in the next section. The same trend was observed with the PMS 2 (see Figure $4 \mathrm{f}$ ) as the particles were fully dry at the temperature of $400^{\circ} \mathrm{C}$. A detailed analysis of the particle size distributions at different flow rates is given in the next section.

\section{Effect of Turbine on Particle Number Distribution}

In previous section, results on the effect of turbine on the total PN emissions were presented. This section presents the effect of turbine on particles number distribution. Particle number distribution can provide further exploration to understand the nature of change in the particles based on their sizes. As higher number of particles were emitted from the engine in the 800 bar case, plots were made with the 800 bar injection cases so that the magnitude of changes in PN across the turbine can be shown clearly from the graphical point of view. An example case (see Figure 5) shows the effect of fuel injection pressure on particle number distribution at the turbine
FIGURE 5 Effect of fuel injection pressure on particle number distribution at the turbine inlet particle emission (engine out emission) - An example case

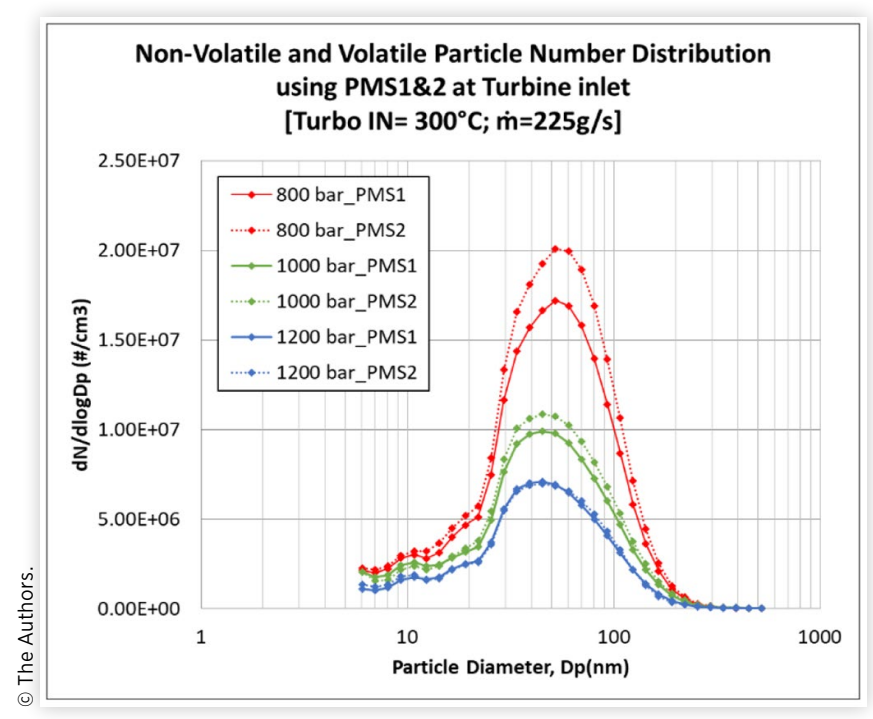

inlet particle emission (engine out emission). The $\mathrm{x}$-axis represents the particle diameter (geometric mean of the measurement interval) and y-axis represents the number concentration of particles in the measurement size interval.

Figure 6 shows the Particle Number Distribution at 800 bar using PMS1 and PMS2. The left hand side (sub-figures a, $\mathrm{b}$ and c) of Figure 6 presents the results using the particle measuring system (PMS1) including a heater at $350^{\circ} \mathrm{C}$ implying that the volatile material has been evaporated prior to detection of the particles. Whereas the right hand side (subfigures $d$, e and f) of Figure 6 presents the results using the particle measuring system (PMS2) including a heater at $150^{\circ} \mathrm{C}$ implying that the volatile material is included in the detection of particles.

From Figure 6a, an increase in particles in the size range of $10 \mathrm{~nm}-200 \mathrm{~nm}$ was noted for all three flows while using PMS1. On the other hand, with Figure $6 \mathrm{~d}$ no clear trend of increase with particles in the same size range was observed using PMS2. The change in total $\mathrm{PN}$ at $200^{\circ} \mathrm{C}$ was positive with PMS1 showing an increase in $\mathrm{PN}$ across the turbine (seen in Figure 4a and in Figure 6a). The increase in PN was weak with PMS2 (seen in Figure 4d). Furthermore, the number distribution (seen in Figure $6 \mathrm{~d}$ ) was random showing no trend with respect to mass flow rates owing to the volatile material binding the particles in the process of measurement. This is the reason for particle measurements by PMP requirements has a minimum temperature in the evaporation tube as $300^{\circ} \mathrm{C}$ to remove the volatile material [18]. As the temperature at the turbine inlet was $200^{\circ} \mathrm{C}$ (which is $<300^{\circ} \mathrm{C}$ ), the volatile material among particles could have remained across the turbine.

Analysis of the particle number distribution at $300^{\circ} \mathrm{C}$ at 800 bar was done to understand the increase in particles earlier noted with Figure $4 \mathrm{~b}$ and Figure 4e. Figure 6b shows the Particle Number Distribution at 800 bar with different mass flow rates at Turbo IN temperature of $300^{\circ} \mathrm{C}$ using PMS1. From Figure $6 \mathrm{~b}$, by comparing each outlet (dotted line) with 
FIGURE 6 Particle Number Distribution at 800 bar using PMS1 and PMS2
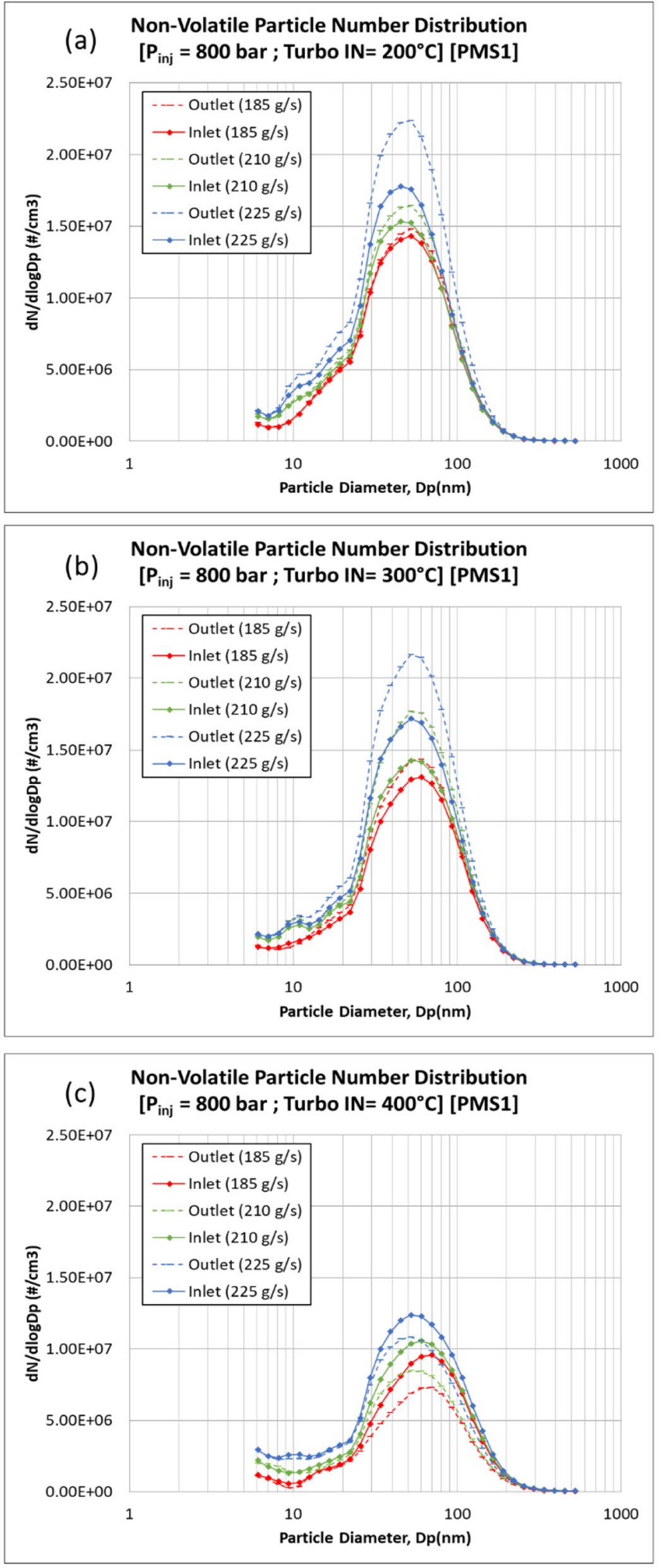

its corresponding inlet (solid line) of the turbine, it can be seen that the increase in the maximum number of particles was exhibited with all three mass flow rates. The magnitude of the increase was larger for higher flow rates. Furthermore, the increase was observed among the particles in the range of 30
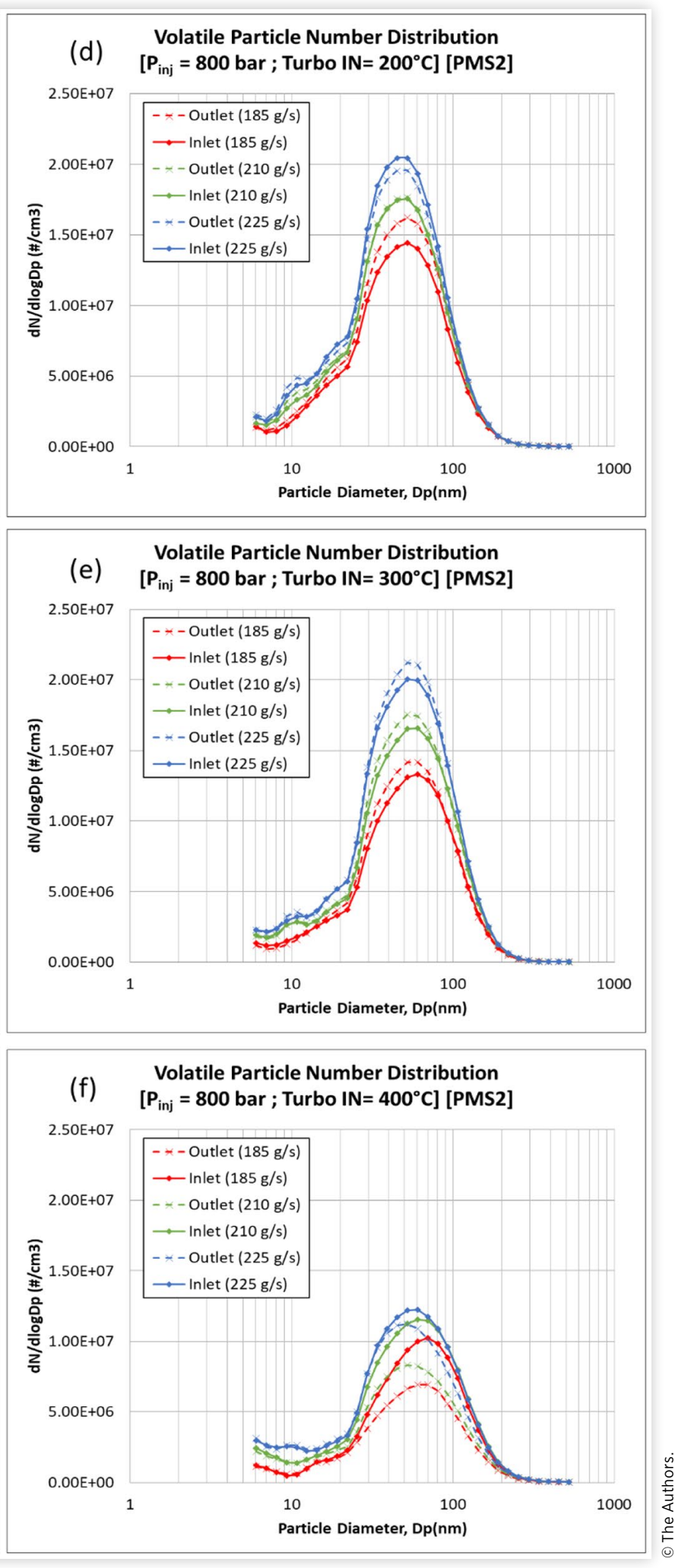

$\mathrm{nm}-200 \mathrm{~nm}$ (mostly accumulation mode particles) while there was not much change among the nuclei mode particles. The increase at $300^{\circ} \mathrm{C}$ could be due to the fragmentation of larger size particles into smaller size particles. The fragmentation is explained with the volume distribution in Figure 7. The 
FIGURE 7 Particle Volume Distribution at 800 bar with different mass flow rates at Turbo IN temperature of $300^{\circ} \mathrm{C}$

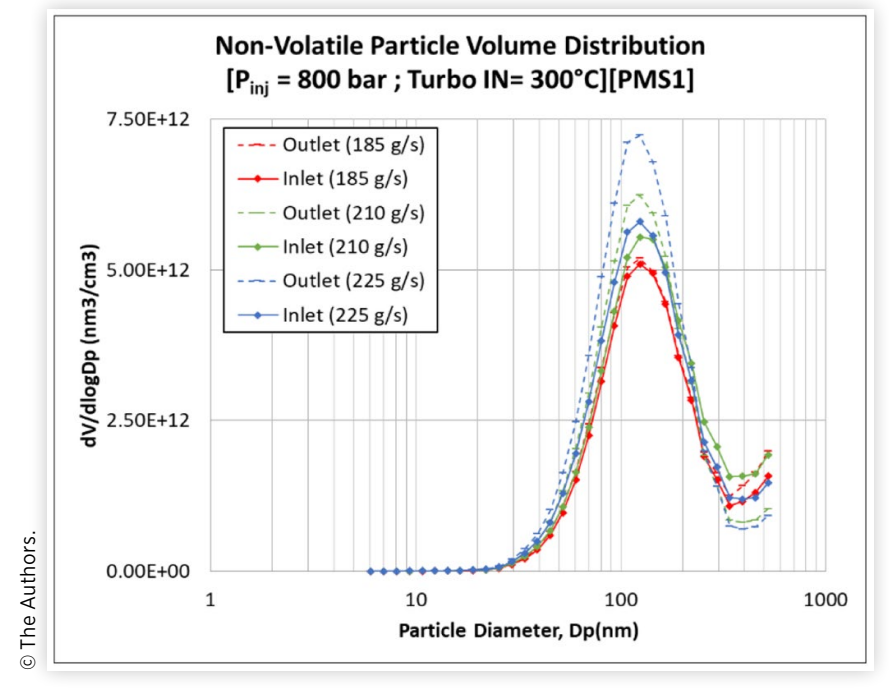

increasing trend was as well noted with PMS2 but with different magnitudes due to sticking together with volatile material (see Figure 6e).

Figure 7 shows the Particle Volume Distribution at 800 bar with different mass flow rates at Turbo IN temperature of $300^{\circ} \mathrm{C}$. The $\mathrm{x}$-axis represents the particle diameter (geometric mean of the measurement interval) and $y$-axis represents the volume concentration of particles in the measurement size interval.

From Figure 7, it can be noticed that the decrease of larger size particles (in the range of $200 \mathrm{~nm}-560 \mathrm{~nm}$ ) was exhibited at flow rates of $210 \mathrm{~g} / \mathrm{s}$ and $225 \mathrm{~g} / \mathrm{s}$. At $185 \mathrm{~g} / \mathrm{s}$, larger size particle reduction was not noted, and a slight increase was observed. Figure 7 also shows the increase in smaller accumulation mode particles (in the range of $30 \mathrm{~nm}-200 \mathrm{~nm}$ ), as also observed earlier in Figure 6b. Therefore, a simultaneous reduction of larger particles and an increase of smaller particles can be observed. Furthermore, larger size particles outside the EEPS measurement range $(5.6 \mathrm{~nm}-560 \mathrm{~nm})$ are likely to be present in the exhaust stream. These particles could have also undergone fragmentation.

Figure $6 c$ shows a reduction of particles across the turbine in Particle Number Distribution at 800 bar with different mass flow rates at Turbo IN temperature of $400^{\circ} \mathrm{C}$ using PMS1. By comparing each outlet (dotted line) with its corresponding inlet (solid line) in Figure 6c, it can be seen that the reduction of maximum number of particles was exhibited with all three mass flow rates. Also, it can be observed that the particle diameter $\left(D_{p}\right)$ at the maximum number of particles reduces in the outlet. There was not much reduction of nuclei mode particles. Similar trend was observed with the volatile particles measured using PMS2 (see Figure 6f). The impact on larger size particles can be studied using the volume distribution shown in the later part of the section.

Further analysis was made with the surface distribution of particles to understand the reduction of the peak and diameter. The particle surface distribution was calculated from the particle number distribution measurements,
FIGURE 8 Particle Surface Distribution at 800 bar with different mass flow rates at Turbo IN temperature of $400^{\circ} \mathrm{C}$

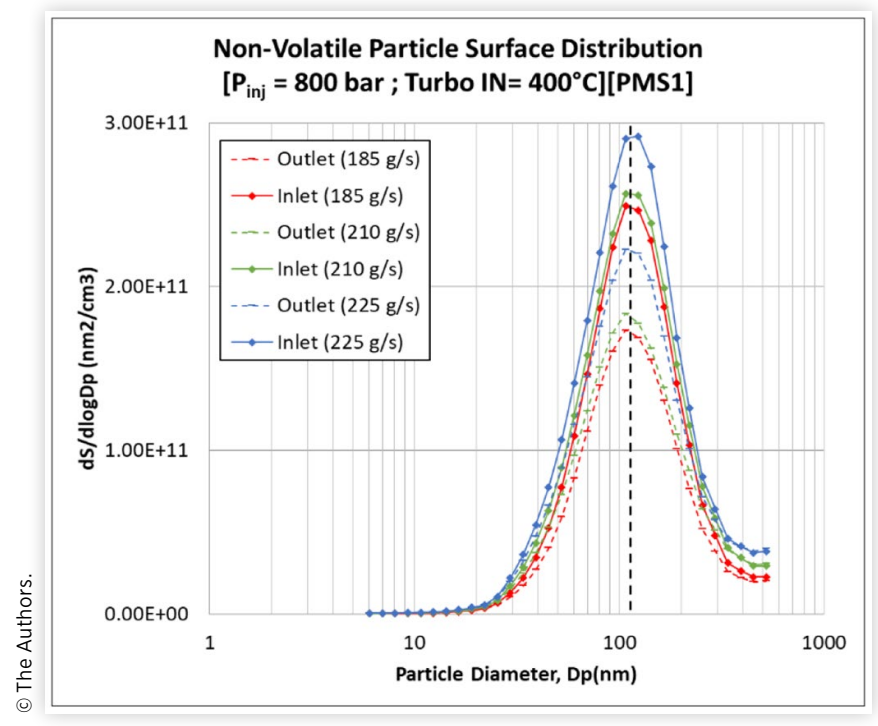

assuming spherical particles (Equation (3)). Figure 8 shows the Particle Surface Distribution at 800 bar with different mass flow rates at Turbo IN temperature of $400^{\circ} \mathrm{C}$. The x-axis represents the particle diameter (geometric mean of the measurement interval) and y-axis represents the surface concentration of particles in the measurement size interval.

Figure 8 shows the decrease in the maximum particle surface area observed between the turbine inlet (solid lines) and outlet (dotted lines) for all three mass flow rates. The surface distribution plot in Figure 8 shows no change in particle diameter at the outlet in comparison to the inlet. Conversely, there was a decrease in the particle diameter seen in particle number distribution plot (see Figure $6 \mathrm{c}$ ). The reduction of the particle surface area was observed approximately centred at a particle size of $100 \mathrm{~nm}$ (shown by vertical black dotted line). From Figure $6 c$ (for smaller size particles) and Figure 8 (for larger size particles) it can be noticed that the reduction was among the particles whose size was ranging from $20 \mathrm{~nm}-200 \mathrm{~nm}$. Further explanations of these trends is provided in the discussion section.

As previously noted in Figure $4 \mathrm{c}$, the total $\mathrm{PN}$ reduction at 1200 bar was less at lowest mass flow rate $(185 \mathrm{~g} / \mathrm{s})$, leading to a further analysis of the particle number distribution for this specific injection pressure. Figure 9 shows the Particle Number Distribution at 1200 bar with different mass flow rates at Turbo IN temperature of $400^{\circ} \mathrm{C}$.

Figure 9 shows that at 1200 bar, a reduction in number of particles over the turbine was observed with all tested flow rates. The data shows similar result as for the 800 bar injection plots (see Figure 6c). A further investigation was made into the volume distribution as described in equation (4). Figure $10 \mathrm{a}$ and Figure 10b shows the Particle Volume Distribution at 800 and 1200 bar with different mass flow rates at Turbo IN temperature of $400^{\circ} \mathrm{C}$ using PMS1.

From the volume distribution at the higher injection pressure shown in Figure 10b, it can be observed that the volume of larger particles $(200-560 \mathrm{~nm})$ at the inlet is 
FIGURE 9 Particle Number Distribution at 1200 bar with different mass flow rates at Turbo IN temperature of $400^{\circ} \mathrm{C}$

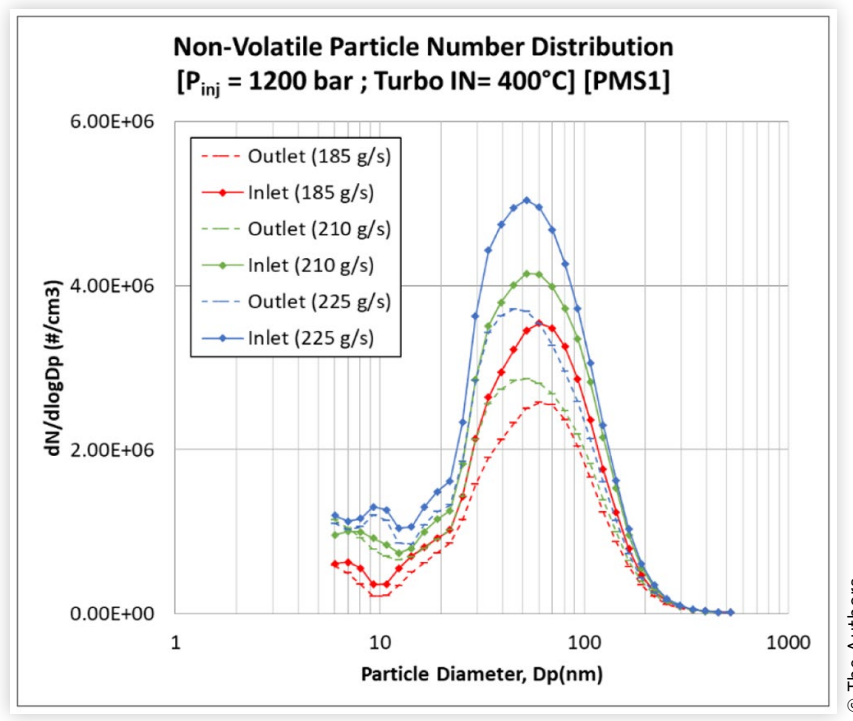

FIGURE 10 Particle Volume Distribution at 800 and 1200 bar with different mass flow rates at Turbo IN temperature of $400^{\circ} \mathrm{C}$ using PMS1

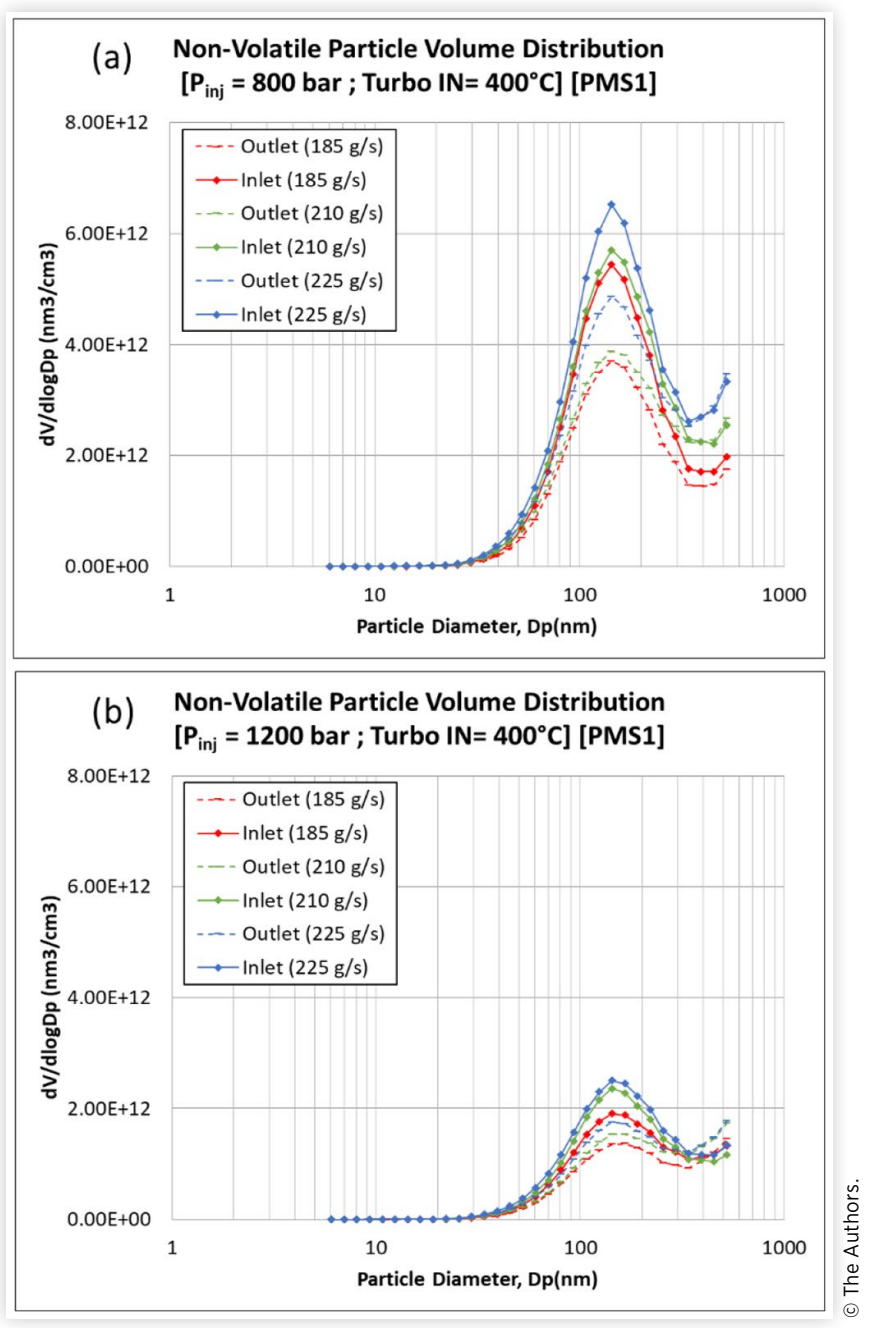

approximately constant with respect to the mass flow rate. Whereas at an injection pressure of 800 bar (see Figure 10a) the number of particles above $200 \mathrm{~nm}$ shows an increase with flow rate at the inlet. Hence the nature of the particles above $200 \mathrm{~nm}$ at the inlet was not similar between 800 bar and 1200 bar. Furthermore, in the volume distribution of 800 bar injection, a reduction of particles above $200 \mathrm{~nm}$ was observed at the lowest mass flow rate $(185 \mathrm{~g} / \mathrm{s})$ but the same was not observed in 1200 bar injection. Further explanations are provided in the discussion section.

\section{Discussion}

The flow field in a turbocharger turbine is inherently unsteady and complex due to the opening-closing of the exhaust valve, as well as due to the presence of upstream exhaust manifold. In addition to the primary flow following the curvature of the scroll and the rotor geometry, the blowdown of the exhaust gas might cause flow impingement on the inner surfaces and consequently induce secondary flow with highly dynamic large-scale rotating vortices [19]. The flow impingement may lead to particle fragmentation while the rotating vortices may lead to agglomeration in the turbine.

When the turbine inlet temperature is $200^{\circ} \mathrm{C}$, for all mass flow rates we observe that the total number of particles measured at the turbocharger outlet has increased compared to the inlet, but the magnitude of the increase was random, and no clear trend (with respect to mass flow rates) could be observed. At the exhaust temperature of $200^{\circ} \mathrm{C}$ in the inlet of the turbine, some of the volatile material remain, binding the particles together. This is the same reason why particle measurements by PMP requirements has a minimum temperature in the evaporation tube as $300^{\circ} \mathrm{C}$ to remove the volatile material [18]. Thus the volatile material have not been fully evaporated by the sample conditioning system with evaporation tube being at $150^{\circ} \mathrm{C}$ showing no change across the turbine. The smaller size particles stays together anyways as they follow the streamline and are least affected by impaction. It could be hypothesized that the presence of volatile material holds the larger size particles together, thereby reducing the fragmentation of large particles since the larger size particles are more susceptible to fragmentation due to impaction.

The simultaneous reduction in number of larger particles $(>200 \mathrm{~nm})$ and increase in number of accumulation mode particles (30-200 nm) observed over the turbine for a turbine inlet temperature of $300^{\circ} \mathrm{C}$ can be explained by particle fragmentation. At $300^{\circ} \mathrm{C}$ in the turbine, the particles are almost without volatile material and thus they can be regarded as solid particles making them prone for fragmentation. With increase in the flow rate, the impaction of larger size particles on the turbine blades increases. This impaction leads to fragmentation of the larger size particles due to their high Stokes number. The fragmentation is in turn shown as an increase in the total number across the turbine. On the other hand, with the increase in injection pressure the emission of larger size particles from the engine reduces due to better mixture preparation [15]. This higher injection pressure results in lesser number of larger size particles to the turbine inlet. As noted 
earlier, larger size particles are more prone to impaction and in turn fragmentation in the turbine. Hence with increasing injection pressures, the increase in particle number across the turbine was less pronounced. In fact, at a higher injection pressure (1200 bar) with the lowest flow rate $(185 \mathrm{~g} / \mathrm{s})$ there was even a reduction observed. The reason is the same as the reduction of particles at $400^{\circ} \mathrm{C}$ which is explained in the next paragraph.

At $400^{\circ} \mathrm{C}$ exhaust temperature at the turbine inlet for all flow rates a significant particle reduction over the turbine was observed in total number and in number distribution. There are three possibilities of reduction on total number of particles (i) thermophoretic loss of particles (ii) agglomeration of particles and (iii) oxidation of particles.

The possibility of thermophoresis is likely when the temperature of the gas flow is high and the wall temperature is lower. Temperature difference is the major driver for thermophoresis to occur [20]. In this experiment, temperature difference across the wall and the flow is high only at the start of the experiments as the exhaust temperature was stabilized for steady state. This means that when measurements were performed, the wall and the exhaust stream had approximately the same temperature. Hence the possibility of thermophoretic losses is not probable.

The next possible explanation for the particle reduction is agglomeration of particles. In agglomeration, many particles unite to form larger size particles which could be observed by simultaneous reduction of smaller size particles along with the increase in larger size particles in the particle size distribution. From the particle size distribution plots, agglomeration was not observed.

The third possibility is the oxidation of particles in the turbine. As the particles are without volatile material in the turbine at $400^{\circ} \mathrm{C}$, they are regarded as solid particles. Therefore, the oxidation reaction could be regarded as a noncatalyzed heterogeneous chemical reaction between solid and gas. In these reactions, the reaction rate is governed by the surface area of the solid [21].

At $400^{\circ} \mathrm{C}$ exhaust temperature at the turbine inlet, the particle number distributions captured at the outlet showed the occurrence of the peak in particle number was shifting towards smaller particle sizes along with the reduction in number. Furthermore, with the surface distribution plot, it was noted that the median size of the particle reduction was on the same particle diameter $(100 \mathrm{~nm})$ for all flows. This particle diameter was the same where the peak of the surface concentration was observed. This suggests the reduction of PN takes place through a surface reaction and it may be enhanced by the contact with the surfaces of the blades in the turbine.

In characterizing diesel soot oxidation by thermogravimetric method, the following was observed in literature [22]. Oxidation of diesel soot starts at a temperature of $275^{\circ} \mathrm{C}$. The triggering oxidation temperature (the temperature at which the mass loss rate $\left(\% /{ }^{\circ} \mathrm{C}\right)$ reaches an inflection point) is between $400^{\circ} \mathrm{C}$ and $450^{\circ} \mathrm{C}$. Complete oxidation of soot occurs at around $600^{\circ} \mathrm{C}$. It is to be considered that in the current study, the temperature measured is the average temperature at the turbine inlet. As the exhaust is pulsating for every valve event, the actual peak temperatures could be higher. This could aid oxidation rate and thus explain the decrease in the number of particles.

At temperatures between $400^{\circ} \mathrm{C}$ and $450^{\circ} \mathrm{C}$, the total mass reduction of soot is not very high as the particle sizes where the number reduction occurs do not contribute much to the volume distribution and in turn the mass of the particles.

At $400^{\circ} \mathrm{C}$, for a given distribution, the rate of oxidation is a function of geometric and material property of the soot particles. When the mass flow rate is less, then the residence time of the particles in the turbine is higher. This might be the reason for higher reduction in PN observed at lower mass flow rates. The reduction in $\mathrm{PN}$ over the turbine is promising, as a catalyst coated turbine wheel could potentially enhance the effect thereby reducing PN before the after-treatment system.

\section{Conclusions}

An experimental campaign was performed on a Euro VI HD diesel engine to evaluate the effect of the turbine in the turbocharger on the particle number emissions with respect to particle number and particle size distribution. Following are the conclusions from the current experimental study.

- At turbine inlet temperatures of $200^{\circ} \mathrm{C}$, the particle number is almost constant across the turbine. This could be due to that the particles are held together by the volatile material.

- At turbine inlet temperatures of $300^{\circ} \mathrm{C}$, particles of size greater than $200 \mathrm{~nm}$ present in the inlet, are dry enough to get fragmented in the turbine. Thus resulting in an increased number of particles at the outlet of the turbine. The fragmentation of particles increases with the increase in mass flow rate through the turbine.

- Oxidation of particles in the range of $20 \mathrm{~nm}-200 \mathrm{~nm}$, occurs in the turbine at temperatures of $400^{\circ} \mathrm{C}$ resulting in a decrease in the number of particles. The median size of particle reduction occurs at $100 \mathrm{~nm}$. The oxidation of particles increases with reduced mass flow rates through the turbine.

\section{References}

1. Lelieveld, J., Klingmüller, K., Pozzer, A., Pöschl, U. et al., "Cardiovascular Disease Burden from Ambient Air Pollution in Europe Reassessed Using Novel Hazard Ratio Functions," European Heart Journal 40(20):1590-1596, 2019, doi:10.1093/ eurheartj/ehz135.

2. Alföldy, B., Giechaskiel, B., Hofmann, W., and Drossinos, Y., "Size-Distribution Dependent Lung Deposition of Diesel Exhaust Particles," Journal of Aerosol Science 40(8):652-663, 2009, doi:10.1016/j.jaerosci.2009.04.009.

3. "Regulation (EC) No. 595/2009 of the European Parliament and of the Council of 18 June 2009 on Type-Approval of Motor Vehicles and Engines with Respect to Emissions from Heavy Duty Vehicles (Euro VI) and on Access to Vehicle 
Repair and Maintenance Information and Amending Regulation (EC) No. 715/2007 and Directive 2007/46/EC and Repealing Directives 80/1269/EEC, 2005/55/EC and 2005/78/ EC," http://data.europa.eu/eli/reg/2009/595/oj, accessed on May 2020.

4. Wang, X., Wang, Y., Bai, Y., Wang, P. et al., "An Overview of Physical and Chemical Features of Diesel Exhaust Particles," Journal of the Energy Institute 92(6):1864-1888, 2019, doi:10.1016/j.joei.2018.11.006.

5. Kittelson, D.B., Watts, W.F., Johnson, J.P., Rowntree, C.J. et al., "Driving Down On-Highway Particulate Emissions," SAE Technical Paper 2006-01-0916, 2006, https://doi. org/10.4271/2006-01-0916.

6. Zhong, D., He, S., Tandon, P., Moreno, M. et al., "Measurement and Prediction of Filtration Efficiency Evolution of Soot Loaded Diesel Particulate Filters," SAE Technical Paper 2012-01-0363, 2012, https://doi. org/10.4271/2012-01-0363.

7. Yang, S., Deng, C., Gao, Y., and He, Y., "Diesel Particulate Filter Design Simulation: A Review," Advances in Mechanical Engineering 8(3):1-14, 2016, doi:10.1177/1687814016637328.

8. Rönkkö, T., Virtanen, A., Kannosto, J., Keskinen, J. et al., "Nucleation Mode Particles with a Nonvolatile Core in the Exhaust of a Heavy Duty Diesel Vehicle," Environmental Science and Technology 41(18):6384-6389, 2007, doi:10.1021/ es0705339.

9. Cucchi, M., and Samuel, S., "Influence of the Exhaust Gas Turbocharger on Nano-scale Particulate Matter Emissions from a GDI Spark Ignition Engine," Applied Thermal Engineering 76:167-174, 2015, doi:10.1016/j. applthermaleng.2014.11.002.

10. Cucchi, M., and Samuel, S., "Application of the Lambert W Function for the Impact of the Exhaust Gas Turbocharger on Nanoscale PM Emissions from a TGDI Engine," Applied Thermal Engineering 99:429-433, 2016, doi:10.1016/j. applthermaleng.2015.12.125.

11. Lee, K.O., and Zhu, J., "Effects of Exhaust System Components on Particulate Morphology in a Light-Duty Diesel Engine," SAE Technical Paper 2005-01-0184, 2005, https://doi.org/10.4271/2005-01-0184.

12. Payri, F., Serrano, J.R., Piqueras, P., and García-Afonso, O., "Performance Analysis of a Turbocharged Heavy Duty Diesel Engine with a Pre-turbo Diesel Particulate Filter Configuration," SAE Int. J. Engines 4(2):2559-2572, 2011, https://doi.org/10.4271/2011-37-0004.

13. Khandai, C., Bakare, A., Petkar, R.M., Babu, K.V.R. et al., "Application of a Pre-turbocharger Catalyst (PTC) on an Indian Multi Utility Diesel Vehicle for Meeting BS IV," SAE Technical Paper 2011-26-0024, 2011, https://doi. org/10.4271/2011-26-0024.

14. Giechaskiel, B., Arndt, M., Schindler, W., Bergmann, A. et al., "Sampling of Non-Volatile Vehicle Exhaust Particles: A Simplified Guide," SAE Int. J. Engines 5(2):379-399, 2012, https://doi.org/10.4271/2012-01-0443.

15. Wu, B.Y., Zhan, Q., Zhang, S.K. et al., "Effect of Heavy-Duty Diesel Engine Operating Parameters on Particle Number and Size Distribution at Low Speed Condition," Int J Automot Technol 19(4):623-633, 2018, doi:10.1007/s12239018-0059-3.
16. TSI, "Updated Inversion Matrices for Engine Exhaust Particle Sizer (EEPS) Spectrometer Model 3090," 2015.

17. Seinfeld, J.H., and Pandis, S.N., Atmospheric Chemistry and Physics: From Air Pollution to Climate Change Second Edition (New York: John Wiley \& Sons, 2006).

18. Giechaskiel, B., Mamakos, A., Andersson, J., Dilara, P. et al., "Measurement of Automotive Nonvolatile Particle Number Emissions within the European Legislative Framework: A Review," Aerosol Science and Technology 46(7):719-749, 2012, doi: $10.1080 / 02786826.2012 .661103$.

19. Lim, S.M., Dahlkild, A., and Mihaescu, M., "Influence of Upstream Geometry on Pulsatile Turbocharger turbine Performance," Proceedings of the ASME Turbo Expo 8:1-10, 2018, doi:10.1115/GT201876706.

20. Sagot, B., "Thermophoresis for Spherical Particles," Journal of Aerosol Science 65:10-20, 2013, doi:10.1016/j. jaerosci.2013.06.007.

21. Wen, C.Y., "Noncatalytic Heterogeneous Solid-Fluid Reaction Models," Industrial and Engineering Chemistry 60(9):34-54, 1968, doi:10.1021/ie50705a007.

22. Rodríguez-Fernández, J., Oliva, F., and Vázquez, R.A., "Characterization of the Diesel Soot Oxidation Process through an Optimized Thermogravimetric Method," Energy and Fuels 25(5):2039-2048, 2011, doi:10.1021/ef200194m.

23. Arun Prasath, K., Stenlaas, O., Bernemyr, H., and Erlandsson, A., "Agglomeration and Nucleation of NonVolatile Particles in a Particle Grouping Exhaust Pipe of a Euro VI Heavy-Duty Diesel Engine," SAE Technical Paper 2019-01-0044, 2019, https://doi.org/10.4271/2019-01-0044.

\section{Contact Information}

\section{Arun Prasath K.}

Competence Centre for Gas Exchange (CCGEx), KTH Royal Institute of Technology, Brinellvägen 83, Stockholm, SE-10044, Sweden karunpr@kth.se

\section{Acknowledgments}

The authors would like to thank Shyang Maw Lim for taking part in the discussion of results. This study was conducted as part of a project within the Competence Center for Gas Exchange (CCGEx) at KTH. The authors would like to acknowledge the Swedish Energy Agency, Volvo Cars, Volvo GTT, Scania, BorgWarner Turbo Systems Engineering, and Wärtsilä for their support and contributions.

\section{Definitions/Abbreviations}
APC - AVL Particle Counter
CO - Carbon monoxide
CoV - Coefficient of Variation
DOC - Diesel Oxidation Catalyst
$\mathbf{D}_{\mathbf{p}}$ - Diameter of the particle
DPF - Diesel Particulate Filter 
EEPS - Engine Exhaust Particle Sizer Spectrometer

ET - Evaporation Tube

GDI - Gasoline Direct Injection

HC - Hydrocarbon

HD - Heavy-Duty

HPR - High Pressure Reducing unit

ICE - Internal Combustion Engines

LD - Light-Duty

n - No. of Particles
$\mathrm{NO}_{\mathbf{x}}$ - Oxides of Nitrogen

PMP - Particle Measurement Programme

PMS - Particle Measurement System

PN - Particle Number

$S$ - Surface Area

SCR - Selective Catalytic Reduction unit

SMPS - Scanning Mobility Particle Sizer

TDC - Top Dead Centre

V - Volume

(c) 2020 The Authors. Published by SAE International. This Open Access article is published under the terms of the Creative Commons Attribution License (http:// creativecommons.org/licenses/by/4.0/), which permits distribution, and reproduction in any medium, provided that the original author(s) and the source are credited.

Positions and opinions advanced in this work are those of the author(s) and not necessarily those of SAE International. Responsibility for the content of the work lies solely with the author(s). 